\title{
The Influence of Lactose Hydrolysis on the Strength and Sensory Characteristics of Vanilla Ice Cream
}

\author{
K. E. Matak, J. H. Wilson, S. E. Duncan, E. J. Wilson, C. R. Hackney, S. S. Sumner
}

\begin{abstract}
Lactose hydrolysis was investigated as a method of producing a more extrudable ice cream product. Ice cream mixes were treated with lactase from the microbial sources Kluyveromyces lactis and Aspergillus oryzae to produce 0\% to $100 \%$ lactose hydrolysis. Compression measurements and yield stress tests of frozen ice cream were both affected by the temperature of the samples. As the temperature decreased, the work required to compress the ice cream $10 \mathrm{~mm}$ (firmness) and the torsional shear stress both increased. There was a linear relationship between the firmness of lactose-hydrolyzed ice cream $(0 \%, 80 \%$, and $100 \%)$ and temperature $\left(r^{2}=0.98,0.99\right.$, and 0.97 , respectively). The treated samples were significantly softer than the control, but not different from each other. There was a significant difference $(p<0.05)$ in ice cream dippability between the control samples (0\% hydrolyzed) and the treatment groups (80\% and $100 \%$ hydrolyzed). The control group was consistently harder to dip. Hydrolysis of lactase in the ice cream mix produced a softer, more extrudable product.
\end{abstract}

Keywords. Dippability, Ice cream, Lactose hydrolysis, Vane method.

$\mathrm{T}$ he dairy industry is continually expanding their product lines to include more specialty items to meet consumer needs and expectations. Extrudable ice creams that are easier to dip at home freezer temperatures are some of the novelty frozen desserts being considered. Dipping characteristics of ice cream may be enhanced by depressing the freezing point, by increasing the air whipped into the product, or by temporarily increasing the storage temperature (Iversen, 1983; Lindamood et al., 1989). In commercial products, improved dipping characteristics have been obtained primarily by freezing point depression (Lindamood et al., 1989).

Freezing point of an ice cream mixture is directly proportional to the number of particles in solution (Iversen, 1983; Mitchell, 1989): the more solids dissolved in the solution, the lower the freezing point. The freezing point varies with the composition of the mix and the concentration of soluble constituents within the mix (Marshall and Arbuckle, 1996). Variations of fat globules, protein, emulsifiers, and stabilizers have no significant effect on the freezing point (Jaskulka et al., 1993).

Article was submitted for review in January 2003; approved for publication by the Food \& Process Engineering Institute Division of ASAE in September 2003. Presented at the 2003 ASAE Annual Meeting as Paper No. 036054.

The authors are Kristen E. Matak, Graduate Student, Department of Food Science and Technology; James H. Wilson, Professor, Department of Biological Systems Engineering; Susan E. Duncan, Associate Professor, Department of Food Science and Technology; Edward J. Wilson, Laboratory Technician, Department of Biological Systems Engineering; Cameron R. Hackney, Professor, Department of Food Science and Technology; and Susan S. Sumner, Department Head, Department of Food Science and Technology, Virginia Tech, Blacksburg, Virginia. Corresponding author: James H. Wilson, Department of Biological Systems Engineering, 210-A Seitz Hall, Virginia Tech, Blacksburg, VA 24061-0303; phone: 540-231 -6809; fax: 540-231-3199; e-mail: jawilson@vt.edu.
Lactose makes up over one third of the solid matter in milk and approximately $20 \%$ of the carbohydrate in ice cream (Marshall and Arbuckle, 1996). Lactose in an ice cream mix is from milk and dairy ingredients from milk solids not fat (MSNF). The percentage of lactose in ice cream is dependent on the amount of MSNF and fat in the mixture. When the enzyme $\beta$-galactosidase is in the presence of lactose, it acts as a catalyst to hydrolyze the lactose to D-glucose and $\mathrm{D}$-galactose, thus increasing the total solids in solution without contributing to the caloric content of the mix (Bakken et al., 1992).

The hardness of frozen ice cream is important when transferring ice cream from one container to another, as occurs during dipping. Textural parameters of firmness and yield stress have been measured mechanically and used to estimate the ease of dipping ice cream (Lindamood et al., 1989; Briggs et al., 1996). Lindamood et al. (1989) evaluated the firmness of $0 \%, 25 \%, 50 \%$, and $100 \%$ lactose-hydrolyzed ice cream samples using compression measurements from a universal testing machine. Non-hydrolyzed ice cream samples had a relative firmness of $0.44 \mathrm{~J}$. The firmness values of the lactose-hydrolyzed samples $(25 \%, 50 \%$, and $100 \%$, respectively) were statistically different $(\mathrm{p}<0.05)$ from those of the control sample $(0.29 \mathrm{~J}, 0.18 \mathrm{~J}$, and $0.13 \mathrm{~J}$, respectively). Some sucrose hydrolysis accompanied the hydrolysis of lactose, contributing to freezing point depression and possibly affecting the firmness of the product. A relationship between ice cream hardness and calculated freezing point depression was established, and it was implied that the hydrolysis of sucrose and lactose in the mix altered the properties of ice cream toward a more "dippable" product (Lindamood et al., 1989). Sensory assessment of dipping characteristics of lactose-hydrolyzed ice creams was not completed.

Ease of dippability of frozen ice cream has also been estimated by determining its yield stress. Yield stress is the minimum stress required to cause flow (Steffe, 1992). Dzuy and Boger (1983) developed a technique (vane method) for 
the direct measurement of the yield stress of concentrated suspensions under static conditions. The vane method is based on the measurement of the yielding moment when a torque exerted on a vane with a small number of blades (usually 2 to 8 ), arranged at equal angles around a small cylindrical shaft, reaches a maximum value (Dzuy and Boger, 1983, 1985). The recorded torque data are divided by the surface area of the cylindrical volume defined by the outer edges of the rotating vane fixture to determine the magnitude of yield stress (Wilson et al., 1993). This method has been employed to calculate the yield stress of food suspensions such as melted chocolate, mayonnaise, tomato concentrates, and salad dressings (Briggs et al., 1996).

The principle of the vane method is centered on extremely slow shearing to detect yielding of material (Dzuy and Boger, 1983). Rotating the vane at low speeds is required to achieve satisfactory yield stress measurements. High rotational speeds (>8 rpm) may introduce errors into the measured maximum torque and hence into the calculated yield stress. This may result from viscous resistance together with instrument inertia and insufficient damping (Dzuy and Boger, 1983). The suitable operating range of vane rotational speeds for red mud was determined to be from 0.1 to $8 \mathrm{rpm}$ (Dzuy and Boger, 1983).

Briggs et al. (1996) assessed the feasibility of the vane method as a means to measure the yield stress in ice cream. This study presented the first use of the vane method for measurements of viscosity of frozen ice cream. Yield stress measurements of two commercially available brands of vanilla and chocolate ice cream were compared. Upon rotation of the sample $(1 \mathrm{rpm})$, the torque on the vane increased until a peak torque was achieved, followed by a gradual decrease in torque. The yield stress was exceeded at peak torque, and the torque decreased as the material structure broke down as flow began. Briggs et al. (1996) concluded that the results demonstrated the suitability of the vane method as a means of measuring the yield stress of ice cream.

The objectives of this project were: (1) to determine changes in freezing point, texture, and ease of dipping vanilla ice cream as a result of lactose hydrolysis, and (2) to relate observations from the sensory dippability study with the firmness and yield stress data to determine if these methods could be used as an alternative to human testing of dippability.

\section{Materials AND Methods}

A vanilla ice cream mix consisting of $10 \%$ milkfat, $11 \%$ milk solids-not fat, $15 \%$ sucrose, and $0.3 \%$ stabilizer was used in this investigation. Non-hydrolyzed vanilla ice cream contains approximately $6 \%$ to $7 \%$ lactose (Carper, 1986). Lactose hydrolysis was accomplished by enzyme preparations from Aspergillus oryzae (fungal source) and Kluyveromyces lactis (yeast source), (Valley Research, Inc., South Bend, Ind.). Enzyme preparations were stored at $4^{\circ} \mathrm{C}$ until addition to the ice cream mix. Enzyme preparations were filtered through sterile $0.45 \mu \mathrm{m}$ acrodiscs (Gelman Sciences Product No. 4184, Fisher Scientific, Pittsburgh, Pa.) and added to $2.3 \mathrm{~L}$ of mix to achieve $100 \%$ hydrolysis.

Lactase activity was determined by blending a dilute enzyme sample with a $0.005 \mathrm{M}$ preparation of $\mathrm{o}$-nitrophe- nyl- $\beta$-D-galactopyranoside (ONGP) (Shah and Jelen, 1990). The amount of o-nitrophenyl released was measured, and the lactase activity was estimated as the amount of enzyme that liberated $1 \mu$ mole of o-nitrophenyl from ONGP per minute per gram of sample at $37^{\circ} \mathrm{C}$ (Shah and Jelen, 1990). The activity levels of the yeast and fungal enzyme were 53,000 ONGP and 30,000 ONGP, respectively.

Enzyme-inoculated ice cream mixes were stored for $24 \mathrm{~h}$ at $4{ }^{\circ} \mathrm{C}$ and shaken vigorously by hand for $1 \mathrm{~min}$ at two different times during the storage period to evenly disperse the enzyme. The degree of hydrolysis achieved after $24 \mathrm{~h}$ was determined based on the amount of lactose and D-galactose in the sample, as measured spectrophotometrically. Sucrose concentration was also assessed (Sucrose/D-Glucose test kit, Boehringer Mannheim, Indianapolis, Ind.) to determine if any hydrolysis occurred as an indication of the specificity of the enzyme preparation.

The hydrolyzed mix was then added to non-hydrolyzed mix immediately before freezing to achieve the desired level of hydrolysis $(0 \%, 80 \%$, and $100 \%$ for the yeast enzyme, and $0 \%$ and $75 \%$ for the fungal enzyme). The degree of lactose hydrolysis was assessed again after the samples were frozen. The freezing point of each mix was measured using a thermistor cyroscope following the procedures of Ohmes et al. (1998).

Ice cream mixes were frozen with approximately $75 \%$ overrun. Ice cream was packaged in $1.1 \mathrm{~L}$ and $0.18 \mathrm{~L}$ plastic freezer containers for the yield stress tests and compression tests, respectively. A 4.6 L container of ice cream was used for sensory tests. All containers were fitted with lids and immediately transferred to a freezer $\left(-20^{\circ} \mathrm{C}\right)$ for storage. The 1.1 L containers were rectangular with dimensions of $95 \times 95$ $\times 120 \mathrm{~mm}$, and the $0.18 \mathrm{~L}$ containers were cylindrical with a diameter of $88 \mathrm{~mm}$ and a height of $40 \mathrm{~mm}$.

Textural characteristics of the ice cream were determined by mechanical and human perceptual methods. Yield stress was determined by the vane method suggested by Steffe (1992) and described by Briggs et al. (1996). A universal testing machine (model 1125, Instron, Canton, Mass.) equipped with a torsion load cell was used to measure the torque required to rotate a vane imbedded in the ice cream samples. A vane with four blades was used in this investigation. The height of the vane was $51 \mathrm{~mm}$, the diameter of the vane was $44 \mathrm{~mm}$, and the thickness of each blade was $1 \mathrm{~mm}$. The dimensions of the vane complied with Steffe's (1992) suggested limits of:

$$
\begin{aligned}
& \mathrm{W} / \mathrm{d}>2.0 \\
& \mathrm{Z}_{1} / \mathrm{d}>1.0 \\
& \mathrm{Z}_{2} / \mathrm{d}>0.5
\end{aligned}
$$

where $W$ is the width of the sample vessel, $d$ is the diameter of the vane, $Z_{1}$ is the distance of the vane from the top of the vessel, and $Z_{2}$ is the distance from the bottom of the vane to the bottom of the vessel (fig. 1).

For each test, the vane was cooled in an ice water bath maintained at $0^{\circ} \mathrm{C}$ prior to testing. The $1.1 \mathrm{~L}$ ice cream sample was held in place by a metal shell with dimensions of $95 \times 95 \mathrm{~mm}$. The vane was submerged $13 \mathrm{~mm}$ below the top surface of the ice cream. To determine if yield stress was affected by rotational speeds, samples hydrolyzed with the fungal-derived lactase were tested $0.01,0.1,1.0$, and 

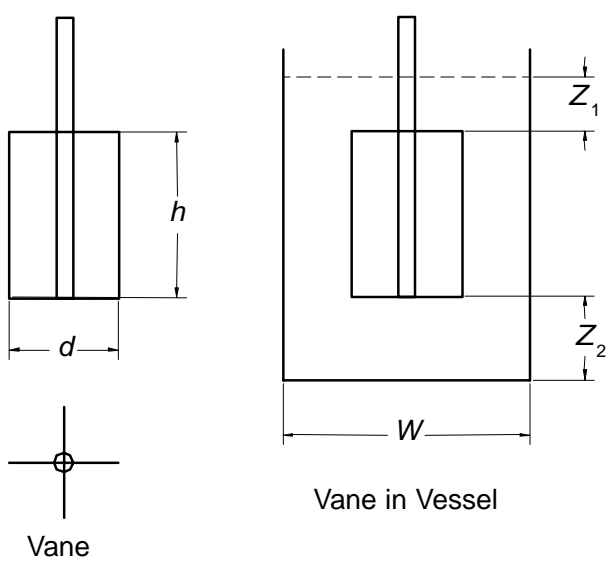

Vane in Vessel

Figure 1. Schematic diagram of the four-bladed vane test apparatus.

$5.0 \mathrm{rpm}$. Maximum torque readings and the angle of rotation at peak torque were obtained on each ice cream sample. The temperature at the center of the ice cream specimen was taken immediately following each test using a thermocouple probe.

The samples hydrolyzed with the yeast lactase were used to determine if the vane method could be used to show a difference in yield stress due to lactose hydrolysis. The specimen rotational speed was set at $0.1 \mathrm{rpm}$ for this series of tests. Maximum torque was obtained on each ice cream sample. Temperatures of the ice cream samples were also taken immediately following each test. The torque values were used to determine the yield stress using the following equation:

$$
\tau_{y}=T_{m} /\left[\pi d^{3} / 2(h / d+1 / 3)\right]
$$

where $\tau_{y}$ is the material yield stress, $T_{m}$ is the maximum torque, and $d$ and $h$ are the vane dimensions (Dzuy and Boger, 1983). This equation neglects end effects, but they were assumed to be small. Dzuy and Boger (1983) compared the results of using equation 1 to two other equations that incorporated end effects. Analysis of their data indicated that the yield stress calculated using equation 1 was essentially the same as that obtained from the other two equations.

Firmness of the frozen ice cream hydrolyzed by the yeast-derived lactose was determined using a universal testing machine (model 100, Instron, Canton, Mass.), as described by Lindamood et al. (1989). Samples from all replications were evaluated the same day to ensure similar test conditions. A cylindrical probe $(6.4 \mathrm{~mm})$, precooled in ice water, was mounted on a $5 \mathrm{~kg}$ transducer and used to take compression force measurements of the ice cream samples. Temperature readings of each ice cream sample were taken immediately following each test using a thermocouple probe. The speed of the crosshead was set at $20 \mathrm{~mm} / \mathrm{min}$ for a depression of $10 \mathrm{~mm}$. The firmness of the ice cream (energy to compress the test sample $10 \mathrm{~mm}$ ) was calculated from the test data. Data from the firmness and yield stress tests were analyzed using ANOVA procedures.

Human subjects were used to determine the ease of dippability for each yeast-derived lactose hydrolysis treatment. Sixteen panelists for each testing period (three testing periods) were recruited and shown the proper way to dip ice cream (Marshall and Arbuckle, 1996). Three paired comparison tests were used to evaluate ease of dippability among samples. The panelists were presented with one pair of coded samples at a time $(0 \%$ and $80 \%, 0 \%$ and $100 \%$, and $80 \%$ and
Table 1. Effects of test speed and hydrolysis on torque and angle of twist (mean $\pm \mathrm{SE}$ ). [a][b]

\begin{tabular}{cccc}
\hline $\begin{array}{c}\text { Speed } \\
(\mathrm{rpm})\end{array}$ & $\begin{array}{c}\text { Hydrolysis } \\
(\%)\end{array}$ & $\begin{array}{c}\text { Torque } \\
(\mathrm{N}-\mathrm{M})^{[\mathrm{c}]}\end{array}$ & $\begin{array}{c}\text { Angle of Twist } \\
(\text { degrees })^{[\mathrm{c}]}\end{array}$ \\
\hline 0.01 & 0 & $1.65 \pm 0.07 \mathrm{a}$ & $12.7 \pm 1.4 \mathrm{a}$ \\
& 75 & $1.27 \pm 0.05 \mathrm{~b}$ & $13.9 \pm 0.9 \mathrm{a}$ \\
\hline 0.10 & 0 & $2.35 \pm 0.23 \mathrm{c}$ & $14.6 \pm 0.5 \mathrm{a}, \mathrm{c}$ \\
& 75 & $1.76 \pm 0.11 \mathrm{a}$ & $14.5 \pm 0.8 \mathrm{a}, \mathrm{c}$ \\
\hline 1.0 & 0 & $5.31 \pm 0.08 \mathrm{~d}$ & $20.1 \pm 1.1 \mathrm{~b}$ \\
& 75 & $3.16 \pm 0.27 \mathrm{e}$ & $17.5 \pm 2.1 \mathrm{~b}, \mathrm{c}$ \\
\hline 5.0 & 0 & $5.65 \pm 0.23 \mathrm{~d}$ & $27.9 \pm 0.9 \mathrm{~d}$ \\
& 75 & $3.58 \pm 0.42 \mathrm{e}$ & $24.9 \pm 0.4 \mathrm{~d}$ \\
\hline
\end{tabular}

[a] Ice cream temperature $=-15.8^{\circ} \mathrm{C} \pm 0.5^{\circ} \mathrm{C}$.

[b] Sample size $n=10$ for 0.10 and $1.0 \mathrm{rpm}$, and $n=3$ for 0.01 and $5.0 \mathrm{rpm}$. [c] Values followed by different letters are statistically different at $\mathrm{P} \leq 0.05$.

$100 \%$ ) in random order. Each panelist evaluated three pairs of samples and indicated which sample was easier to dip within each pair. The panelists dipped the ice cream from samples contained in $4.6 \mathrm{~L}$ containers from a cooler maintained at $-16.5^{\circ} \mathrm{C}$. Significant differences $(\mathrm{p}<0.05)$ between samples were determined using Friedman's analysis (Meilgaard et al., 1991, pp. 103-106).

\section{RESUlTS AND DisCuSSION}

The freezing point of the control ice cream mix was $-1.61{ }^{\circ} \mathrm{C}$. Freezing points of the ice cream with $80 \%$ and $100 \%$ lactose hydrolysis (yeast lactase) were $-2.18^{\circ} \mathrm{C}$ and $-2.22^{\circ} \mathrm{C}$, respectively. Lindamood et al. (1989) calculated freezing points by methods of Iverson (1983). An ice cream containing $10 \%$ milkfat, $12 \%$ milk solids-not fat, $12 \%$ sucrose, $5 \%$ corn syrup (36 DE), and $0.25 \%$ stabilizer-emulsifier blend had a calculated freezing point of $-1.45^{\circ} \mathrm{C}$. Lindamood et al. (1989) also determined that ice cream mixes with $25 \%, 50 \%$, and $100 \%$ lactose hydrolysis had calculated freezing points of $-1.62^{\circ} \mathrm{C},-1.67^{\circ} \mathrm{C}$, and $-1.92^{\circ} \mathrm{C}$, respectively. Differences in the freezing point values between this study and Lindamood et al. (1989) may have existed due to variations in the sugar composition of the mixes.

Table 1 provides a summary of the torque and angle of rotation for the torsional tests conducted at test speeds of $0.01,0.1,1.0$, and $5 \mathrm{rpm}$. Increasing the test speed caused a corresponding increase in torque. There were no statistical differences in the angle of rotation of the test vane for speeds of 0.01 and $0.1 \mathrm{rpm}$, but the angle of rotation increased significantly at both 1.0 and $5.0 \mathrm{rpm}$.

When comparing ice cream temperature to yield stress, changing the torsional speed of the universal testing machine resulted in differences in yield stress of the vanilla ice cream at $0 \%$ hydrolysis (fig. 2). A test speed of $0.1 \mathrm{rpm}$ was selected for the hydrolysis tests comparisons because the change in slope between 1.0 and $5.0 \mathrm{rpm}$ versus 0.1 and $0.01 \mathrm{rpm}$ shown in figure 2 may have been the result of viscous resistance (Dzuy and Boger, 1983). Dzuy and Boger (1983) compared the effect of rotational speed on the measured yield stress of bauxite residue suspensions (red mud). It was determined that at high rotational speeds $(>8 \mathrm{rpm})$, significant viscous resistance together with instrument inertia and insufficient damping may have introduced errors to the measured maximum torque and hence to the calculated yield stress. 


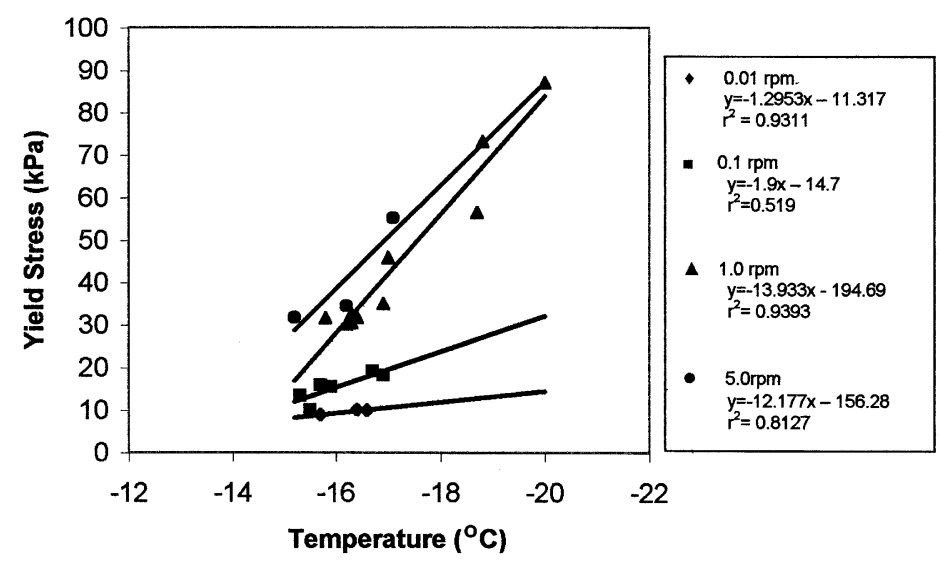

Figure 2. Effects of rotational speed on the yield stress of vanilla ice cream.

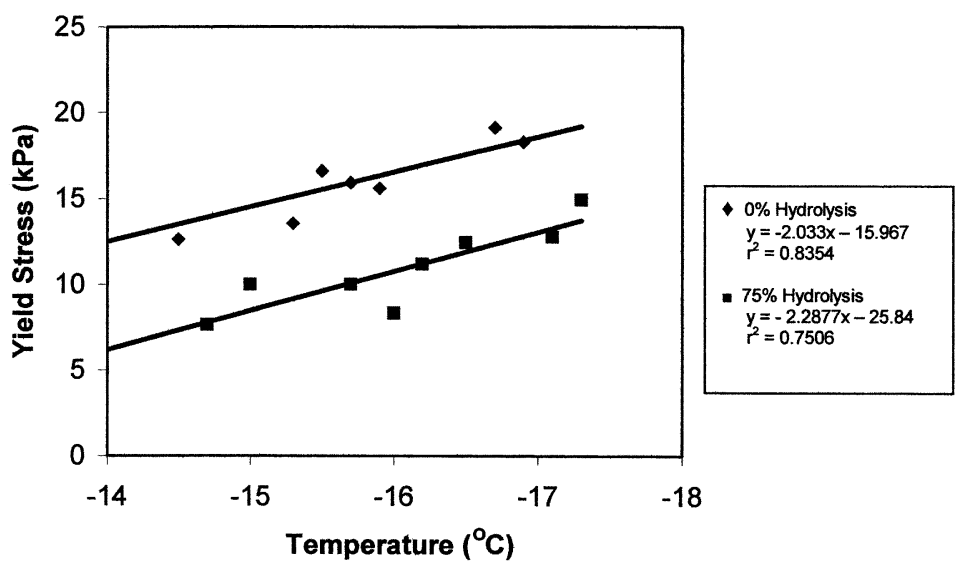

Figure 3. Effects of hydrolysis (fungal source) on the yield stress of vanilla ice cream.

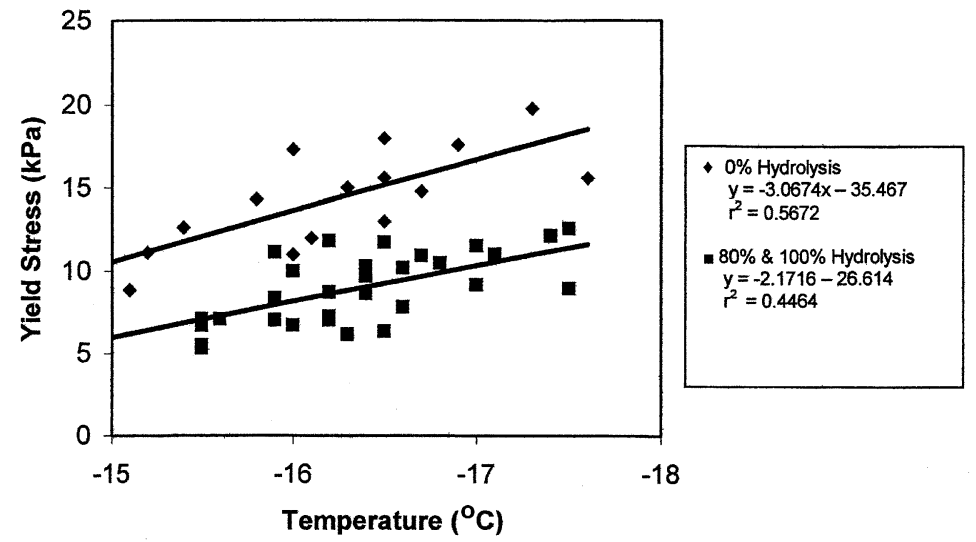

Figure 4. Effects of hydrolysis (yeast source) on the yield stress of vanilla ice cream.

From their results, it was determined that the suitable operating range of vane rotational speeds for red mud should be from 0.1 to $8 \mathrm{rpm}$ (Dzuy and Boger, 1983). Steffe (1992) also noted that when operating in the constant rate mode, use as low a speed as possible but never greater than $1 \mathrm{rpm}$. Higher speeds may alter the results of many products. The speed of $0.01 \mathrm{rpm}$ was not chosen in this investigation because it resulted in a long test time, and there were concerns about a change in ice cream temperature during the test.

The yield stresses of the $0 \%$ and $75 \%$ lactose-hydrolyzed ice cream (fungal lactase source) at $0.1 \mathrm{rpm}$ rotational speed are shown in figure 3. This graph shows that regardless of temperature, the $0 \%$ lactose-hydrolyzed ice cream had a much higher yield stresses than that of the $75 \%$ lactose-hydrolyzed samples. This is significant in showing that the $75 \%$ samples had a lower yield stress, requiring less force to cause flow, which may contribute to "ease of dippability." Briggs et al. (1996) suggested that the ability of ice cream to be dipped is a direct consequence of yield stress and that the vane method may offer an objective way to evaluate the flow behavior of frozen desserts.

Yield stress for ice cream hydrolyzed with yeast lactase, as a function of temperature, is shown in figure 4 . There was 


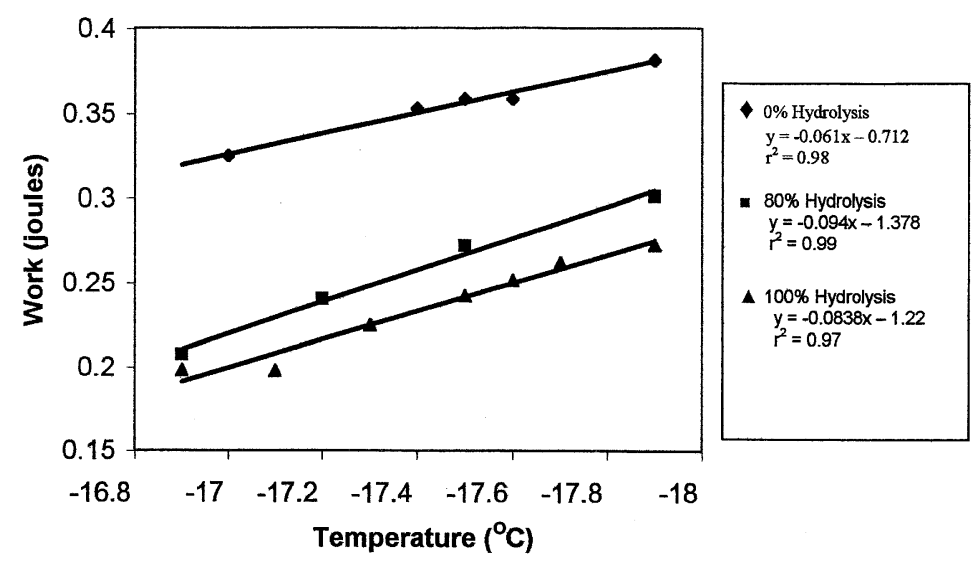

Figure 5. Effects of hydrolysis on the textural firmness of ice cream.

no significant difference between the $80 \%$ and $100 \%$ lactose-hydrolyzed samples; therefore, the data was pooled. The yield stress of the control ( $0 \%$ hydrolyzed) group was statistically higher (fig. 4) than that of the lactose-hydrolyzed group.

The effects of lactose hydrolysis (yeast-based lactase enzyme) on the textural firmness of the ice cream, as determined from the compression tests, are shown figure 5. There was a linear relationship between the firmness of lactose-hydrolyzed ice cream $(0 \%, 80 \%$, and 100\%) and temperature $\left(\mathrm{r}^{2}=0.98,0.99\right.$, and 0.97 , respectively). The firmness of the treated samples was significantly less than that of the control samples, but not different from each other.

Lindamood et al. (1989) suggested that ice cream softness and extrudability could be enhanced by freezing point depression. In the present study, a group of 16 trained panelists determined that there was a significant difference $(\mathrm{p}<0.05)$ in "ease of dippability" between the control $(0 \%$ hydrolysis) and both the $80 \%$ and $100 \%$ treatments (yeast lactase). The control product was consistently harder to dip. To produce $100 \%$ hydrolysis, the addition of $2.5 \mathrm{~mL}$ of yeast enzyme or $13 \mathrm{~mL}$ of fungal enzyme added to $2.3 \mathrm{~L}$ of mix and stored for $24 \mathrm{~h}$ at $4^{\circ} \mathrm{C}$ was required. Because of the high amount of fungal enzyme required, the ice cream mix had an off-flavor. For this reason, no sensory tests were performed on the fungal-based ice cream. The observation of the off-flavor produced by this enzyme was not observed prior to this investigation. This research, to determine the requirement for the amount of fungal enzyme to achieve the desired lactose hydrolysis, was the first assessment of sensory properties related to this enzyme.

\section{Conclusions}

The results of this study indicated that the effects of lactose hydrolysis on the dipping characteristics of ice cream could be evaluated successfully using the vane method, compression method, and/or sensory evaluation. Conclusions from this investigation are that yield stress of vanilla ice cream increased with a decrease in temperature, ice cream firmness increased with a decrease in temperature, increasing shear test speed caused an increase in shear stress, and hydrolysis of lactose in the ice cream mix produced a softer, more easily dippable product. The implication of this research is that consumers with impaired or weakened arm strength may find value in this textural change.

\section{ACKNOWLEDGEMENTS}

The authors express their appreciation to Walter Hartman, Donnie Wingo, Harriet Williams, and Joe Boling for their technical support in this project. The authors also express their appreciation to Valley Research, Inc., South Bend, Indiana, for funding and enzymes for this project and to Shenandoah's Pride Dairy, Mt. Crawford, Virginia, for donating the fluid mix for the ice cream.

\section{REFERENCES}

Bakken, A. P., C. G. Hill, and C. H. Amundson. 1992. Hydrolysis of lactose in skim milk. Biotech. and Bioeng. 39(4): 408-417.

Briggs, J. L., J. F. Steffe, and Z. Ustunol. 1996. Vane method to evaluate the yield stress of frozen ice cream. J. Dairy Science 79(4): 527-531.

Carper, S. 1986. No Milk Today: How to Live with Lactose Intolerance. New York, N.Y.: Simon and Shuster.

Dzuy, N. Q., and D. V. Boger. 1983. Yield stress measurement for concentrated suspensions. J. Rheology 27(4): 321-349.

Dzuy, N. Q., and D. V. Boger. 1985. Direct yield stress measurement with the vane method. J. Rheology 29(3): 335-347.

Iversen, E. K. 1983. Scoopable ice cream. N. European Dairy J. 49(5): 116-122.

Jaskulka, F. J., D. E. Smith, and K. Larntz. 1993. Comparison of the predictive ability of ice cream freezing point depression equations. Milchwissenschaft 48(12): 670-674.

Lindamood, J. B., D. J. Grooms, and P. M. T. Hanson. 1989. Effect of hydrolysis of lactose and sucrose on firmness of ice cream. Food Hydrocolloids 3(5): 379-388.

Marshall, R. T., and W. S. Arbuckle. 1996. Ice Cream. 5th ed. New York, N.Y.: Chapman and Hall.

Meilgaard, M., G. V. Civille, and B. T. Carr. 1991. Sensory Evaluation Techniques. 2nd ed. Boca Raton, Fla.: CRC Press.

Mitchell, G. E. 1989. The contribution of lactose, chloride, citrate, and lactic acid to the freezing point of milk. Australian J. Dairy Tech. 44(2): 61-64.

Ohmes, R. L., R. T. Marshall, and H. Heyman. 1998. Sensory and physical properties of ice creams containing milk fat or fat replacers. J. Dairy Science 81(5): 1222-1228.

Shah, N., and P. Jelen. 1990. Survival of the lactic acid bacteria and their lactases under acidic conditions. J. Food Science 55(2): 506-509

Steffe, J. F. 1992. Rheological Methods in Food Process Engineering. East Lansing, Mich.: Freeman Press.

Wilson, L. L., R. A. Speers, and M. A. Tung. 1993. Yield stresses in molten chocolate. J. Texture Studies 24(3): 269-286. 
